\title{
Hubungan Karakteristik Perawat dan Karakteristik Organisasi dengan Perilaku Caring Perawat Pelaksana di Ruang Rawat Inap Rumah Sakit Kartika Husada Pontianak 2017
}

\author{
Sri Ariyanti' ${ }^{1}$ Muhammad Hadi², Fitri Arofiati ${ }^{3}$ \\ 1,2,3 Fakultas IImu Keperawatan Universitas Muhammadiyah Jakarta \\ email: sriariyantiskepners@yahoo.co.id
}

\begin{abstract}
Caring behavior is an essential component of hospital's quality of service. The patient satisfication's survey shows the lack of caring behavior of associate nurses in Kartika Husada hospital. The purpose of this study was to identify caring behavior and its associated factors in Kartika Husada hospital, Pontianak. This study was a cross sectional study. The data were collected through self administered questionnairein 104 nurses in April- June. Data was analyzed using univariat, bivariate, and multivariate analysis (multiple logistic regression). The result of the study shows there was a significant relationship between communication pattern with caring behavior of nurses in Kartika Husada hospital, Pontianak. This study suggests that nurse manager should be a good mediator to improve caring behavior of nurses.
\end{abstract}

Keywords: caring behavior, hospital, nurses

\section{ABSTRAK}

Perilaku caring perawat merupakan salah satu komponen esensial dari mutu layanan rumah sakit. Hasil survei kepuasan pasien mengindikasikan kurangnya perilaku caring perawat pelaksana di ruang rawat inap Rumah Sakit Tk. II Kartika Husada Pontianak. Tujuan dari penelitian ini adalah untuk mengetahui gambaran perilaku caring serta faktor faktor yang berhubungan dengan perilaku caring perawat pelaksana di ruang rawat inap Rumah Sakit Tk. II Kartika Husada Pontianak. Rancangan penelitian ini adalah crosssectional menggunakan pendekatan kuantitatif. Data dikumpulkan melalui self administered kuesioner terhadap 104 perawat pelaksana pada bulan April-Juni 2017 di ruang rawat inap Rumah Sakit Kartika Husada Pontianak. Analisis data meliputi analisis univariat, bivariat dengan uji chi square dan multivariat dengan regresi logistic ganda. Hasil penelitian menunjukkan terdapat hubungan antara pola komunikasi dengan perilaku caring perawat pelaksana di ruang rawat inap rumah sakit kartika husada pontianak. Manajemen keperawatan dapat menjadi mediator yang baik untuk meningkatkan upaya bagi perawat pelaksana dalam meningkatkan perilaku caring 


\section{PENDAHULUAN}

Kualitas pelayanan kesehatan yang bermutu tentunya hanya dapat dihasilkan oleh sumber daya yang berkualitas, sarana dan prasarana yang mendukung, serta sistem manajerial dan kepemimpinan yang efektif. Wuryanano (2008) mengatakan bahwa manusia adalah kunci keberhasilan suatu organisasi. Begitu pula dengan Rumah Sakit, sumber daya manusianya baik tenaga kesehatan maupun non kesehatan adalah penggerak utama institusi pemberi jasa pelayanan kesehatan ini. Sumber daya manusia yang paling berperan di Rumah Sakit adalah perawat. Hasil survei kepuasan pasien yang dilakukan oleh pihak Rumah Sakit Kartika Husada Pontianak pada tahun 2016 melaporkan 78\% pasien puas.

Hasil penelusuran peneliti dengan manajer keperawatan terkait survei kepuasan pasien menyebutkan bahwa banyak ditemukan keluhan pada pelayanan paramedis di rawat inap, terutama yang terkait dengan perilaku caring perawat. Peran perawat sebagai salah satu sumber daya yang memberikan layanan di rumah sakit adalah memberikan asuhan keperawatan yang berasaskan sikap, perilaku dan pengetahuan yang manusiawi. Sikap dan perilaku yang harus dikembangkan oleh perawat salah satunya yaitu perilaku caring.

Perilaku caring merupakan bentuk kinerja perawat yang dapat dipengaruhi oleh usia, jenis kelamin, pendidikan, status pernikahan dan masa kerja. Terbentuknya perilaku caring juga sangat dipengaruhi oleh sistem nilai bersama yang dianut oleh para perawat yang tercermin dalam visi, misi, dan tujuan rumah sakit.
Tujuan, motivasi karyawan dan struktur manajemen yang kuat mencerminkan organisasi yang kuat sehingga akan membawa dampak pada peningkatan prestasi organisasi dan kinerja anggota organisasi. Kinerja seorang perawat akan baik jika pengaturan kinerja diatur dengan maksimal dengan memperhatikan faktor indivdu dan sistem manajemen kinerja organisasi.

Perilaku caring juga dipengaruhi oleh variabel psikologi yaitu persepsi, sikap, belajar dan motivasi serta variabel organisasi yaitu sumber daya, desain pekerjaan, struktur, imbalan dan kepemimpinan. Selain itu berbagai penelitian sebelumnya menunjukkan bahwa beban kerja, pengembangan profesional, faktor image dan penghasilan berhubungan dengan perilaku caring perawat.

Penelitian ini diperkuat oleh penelitian Muttaqin tahun 2008 yang mendapatkan bahwa perilaku caring meningkat setelah dilakukan supervisi. Penelitian ini bertujuan untuk mengetahui hubungan faktor individu dan beberapa faktor budaya organisasi yang lain yaitu meliputi kepemimpinan, desain pekerjaan, dukungan manajemen, sistem rewards, manajemen konflik dan pola komunikasi dengan perilaku caring perawat pelaksana di ruang rawat inap Rumah Sakit Kartika Husada Pontianak

\section{METODE}

Penelitian ini dilakukan di Rumah Sakit Kartika Husada Pontianak pada Bulan April-Juni 2017 dengan rancangan cross-sectional. Sebanyak 104 perawat pelaksana yang bekerja di ruang rawat inap kelas I, II, III, VIP dan perinatologi diminta persetujuannya untuk berpartisipasi dalam penelitian. 
Variabel yang diukur adalah perilaku caring perawat pelaksana di ruang rawat inap Rumah Sakit Kartika Husada Pontianak sebagai variabel terikat, sedangkan variabel bebas dalam penelitian ini adalah karakteristik perawat yaitu usia, jenis, kelamin, pendidikan, masa kerja, status perkawinan dan karakteristik organisasi, dimana masingmasing variabel yaitu kepemimpinan dan desain pekerjaan dibentuk dari 8 pernyataan, variabel dukungan manajemen dan sistem rewards terdapat 6 pernyataan, variabel manajemen konflik dan pola komunikasi sebanyak 6 pernyataan. Pernyataan untuk variabel perilaku caring dan karakteristik organisasi berskala Likert 1 sampai dengan 5 , dimana pernyataan nilai 1 untuk jawaban tidak pernah atau sangat tidak setuju sampai nilai 5 untuk jawaban selalu atau sangat setuju. Variabel karakteristik organisasi dan perilaku caring akan dikategorikan baik apabila sama dengan mean dan kategori kurang baik apabila kurang dari mean.

\section{HASIL PENELITIAN}

Tabel 1. Distribusi Frekuensi Karakteristik Perawat Di Ruang Rawat Inap Rumah Sakit Kartika Husada Pontianak Tahun 2017, N=104

\begin{tabular}{|c|c|c|}
\hline Karakteristik & Frekuensi (f) & $\%$ \\
\hline \multicolumn{3}{|l|}{ Umur } \\
\hline 20-30 Tahun & 89 & 85,6 \\
\hline$\geq 30$ Tahun & 15 & 14,4 \\
\hline \multicolumn{3}{|l|}{ Jenis Kelamin } \\
\hline Laki-laki & 30 & 28,8 \\
\hline Perempuan & 74 & 71,2 \\
\hline \multicolumn{3}{|l|}{ Tingkat Pendidikan } \\
\hline DIII & 93 & 89,4 \\
\hline Ners & 11 & 10,6 \\
\hline \multicolumn{3}{|l|}{ Masa Kerja } \\
\hline 1-5 Tahun & 88 & 84,6 \\
\hline$\geq 5$ Tahun & 16 & 15,4 \\
\hline \multicolumn{3}{|l|}{ Status Perkawinan } \\
\hline Belum Menikah & 47 & 45,2 \\
\hline Menikah & 57 & 54,8 \\
\hline
\end{tabular}

Berdasarkan tabel tersebut diatas menunjukkan sebagian besar umur perawat adalah kelompok umur 2030 tahun sebanyak 89 orang $(85,6 \%)$. Ini memperlihatkan bahwa rata-rata perawat berada dalam rentang usia produktif. Perawat pelaksana didominasi oleh perawat perempuan $(74 \%)$ lebih banyak dari laki-laki, sedangkan untuk kategori pendidikan, ditemukan tingkat DIII $(89,4 \%)$ lebih banyak dari Ners. Untuk masa kerja ditemukan lebih banyak responden yang bekerja kurang dari 5 tahun $(84,6 \%)$. Perawat pelaksana yang menjadi responden dalam penelitian ini sebagian besar $(54,8 \%)$ dengan status menikah.

\section{Tabel 2. Distribusi Frekuensi Karakteristik Organisasi Perawat Pelaksana di Ruang Rawat Inap Rumah Sakit Tingkat II Kartika Husada Pontianak Tahun 2017, N=104}

\begin{tabular}{|c|c|c|}
\hline $\begin{array}{l}\text { Karakteristik } \\
\text { Organisasi }\end{array}$ & Frekuensi (f) & $\%$ \\
\hline \multicolumn{3}{|l|}{ Kepemimpinan } \\
\hline Kurang Baik & 48 & 46,2 \\
\hline Baik & 56 & 53,8 \\
\hline \multicolumn{3}{|l|}{ Desain Pekerjaan } \\
\hline Kurang Baik & 40 & 38,5 \\
\hline Baik & 64 & 61,5 \\
\hline \multicolumn{3}{|l|}{ Dukungan } \\
\hline \multicolumn{3}{|l|}{ Manajemen } \\
\hline Kurang Baik & 48 & 46,2 \\
\hline Baik & 56 & 53,8 \\
\hline \multicolumn{3}{|l|}{ Sistem Rewards } \\
\hline Kurang Baik & 48 & 46,2 \\
\hline Baik & 56 & 53,8 \\
\hline \multicolumn{3}{|c|}{ Manajemen Konflik } \\
\hline Kurang Baik & 49 & 47,1 \\
\hline Baik & 55 & 52,9 \\
\hline \multicolumn{3}{|l|}{ Pola Komunikasi } \\
\hline Kurang Baik & 50 & 48,1 \\
\hline Baik & 55 & 51,9 \\
\hline
\end{tabular}


Kartika Husada Pontianak Tahun 2017 adalah kepemimpinan (kurang baik $46,2 \%$, baik $53,8 \%$ ), desain pekerjaan (kurang baik $38,5 \%$, baik $61,5 \%$ ), dukungan manajemen (kurang baik $46,2 \%$, baik $53,8 \%$ ), sistem rewards (kurang baik $46,2 \%$, baik $53,8 \%$ ), manajemen konflik (kurang baik $47,1 \%$, baik $52,9 \%$ ) dan pola komunikasi (kurang baik $48,1 \%$, baik $51,9 \%$ ).

Tabel 3. Gambaran Perilaku Caring Perawat Pelaksana Di Ruang Rawat Inap Rumah Sakit Tingkat II Kartika Husada Pontianak Tahun 2017, N=104

\begin{tabular}{|c|c|c|}
\hline Perilaku Caring & $f$ & $\%$ \\
\hline \multicolumn{3}{|c|}{ Mengakui Keberadaan } \\
\hline \multicolumn{3}{|l|}{ Pasien } \\
\hline Kurang Baik & 52 & 50 \\
\hline Baik & 52 & 50 \\
\hline \multicolumn{3}{|c|}{ Menanggapi Dengan Rasa } \\
\hline \multicolumn{3}{|c|}{ Hormat } \\
\hline Kurang Baik & 52 & 50 \\
\hline Baik & 52 & 50 \\
\hline \multicolumn{3}{|l|}{ Pengetahuan Dan } \\
\hline \multicolumn{3}{|c|}{ Keterampilan Yang } \\
\hline \multicolumn{3}{|c|}{ Profesional } \\
\hline Kurang Baik & 48 & 46,2 \\
\hline Baik & 56 & 53,8 \\
\hline \multicolumn{3}{|c|}{ Menciptakan Hubungan } \\
\hline \multicolumn{3}{|l|}{ Positif } \\
\hline Kurang Baik & 47 & 45,2 \\
\hline Baik & 57 & 54,8 \\
\hline \multicolumn{3}{|c|}{ Perhatian Terhadap Apa } \\
\hline \multicolumn{3}{|c|}{ Yang Dihadapi Orang Lain } \\
\hline Kurang Baik & 51 & 49 \\
\hline Baik & 53 & 51 \\
\hline
\end{tabular}

Pada tabel tersebut diatas dapat

dilihat bahwa variabel perilaku caring perawat pelaksana di ruang rawat inap Rumah Sakit Tingkat II Kartika Husada Pontianak Tahun 2017 adalah mengakui keberadaan pasien (kurang baik 50\%, baik 50\%), menanggapi dengan rasa hormat (kurang baik 50\%, baik 50\%), pengetahuan dan keterampilan yang profesional (kurang baik $46,2 \%$, baik $53,8 \%$ ), menciptakan hubungan positif (kurang baik $45,2 \%$, baik $54,8 \%$ ), perhatian terhadap apa yang dialami orang lain (kurang baik $49 \%$, baik $51 \%$ ).

Tabel 4. Hubungan antara Pola Komunikasi dengan Perilaku Caring Perawat Pelaksana di Rumah Sakit Tingkat II Kartika Husada Pontianak Tahun 2017

\begin{tabular}{rc}
\hline Variabel & P Value \\
\hline Pola Komunikasi & 0,000 \\
\hline
\end{tabular}

Hasil penelitian ini adalah terdapat hubungan yang signifikan antara pola komunikasi dengan perilaku caring perawat pelaksana di Rumah Sakit Kartika Husada Pontianak.

\section{PEMBAHASAN}

\section{Perilaku Caring Perawat Pelaksana}

Hasil penelitian menunjukkan bahwa perawat yang berperilaku caring meliputi mengakui keberadaan pasien (kurang baik $50 \%$, baik $50 \%$ ), menanggapi dengan rasa hormat (kurang baik $50 \%$, baik $50 \%$ ), pengetahuan dan keterampilan yang profesional (kurang baik $46,2 \%$, baik $53,8 \%$ ), menciptakan hubungan positif (kurang baik $45,2 \%$, baik $54,8 \%$ ), perhatian terhadap apa yang dialami orang lain (kurang baik $49 \%$, baik $51 \%$ ). Dilihat dari analisa kuesioner mengakui keberadaan pasien didapatkan sebanyak $7,7 \%$ perawat tidak pernah menanyakan nama panggilan yang disenangi pasien, memanggil nama pasien dengan nama panggilan tersebut, 4,8\% perawat tidak pernah memfasilitasi pasien untuk memenuhi keinginannya terhadap alternatif tindakan keperawatan dan pengobatan untuk memperoleh kesehatan, selama tidak bertentangan dengan penyakit dan kesembuhannya.

$$
\text { Menanggapi dengan rasa }
$$

hormat didapatkan 1,9\% perawat tidak 
pernah mengobservasi pasien secara rutin dan teratur, $1,9 \%$ perawat tidak pernah menjaga privasi pasien misalnya dengan memasang sampiran saat melakukan tindakan keperawatan, meminta maaf saat akan melepas pakaian pasien. Pengetahuan dan keterampilan profesional didapatkan $5,8 \%$ perawat tidak pernah memberikan penjelasan secara rasional ketika pasien menanyakan tentang perkembangan penyakitnya dan cara mengatasinya. Menciptakan hubungan positif didapatkan 3,8\% perawat tidak pernah memotivasi pasien untuk berdoa/beribadah sesuai agamanya. Perhatian terhadap yang dialami orang lain didapatkan 1,9\% perawat tidak mengobservasi kondisi kesehatan pasien secara teratur.

Hal ini perlu menjadi perhatian bersama dari pimpinan, karena perilaku caring telah menjadi faktor utama dalam memberikan pelayanan perawatan kepada pasien. Berdasarkan teori Lawrence Green (1980) perilaku manusia dipengaruhi oleh dua faktor pokok, yaitu faktor perilaku (behavior causes) dan faktor diluar perilaku (non behaviour causes). Perilaku terbentuk dari tiga faktor, dimana salah satu faktornya adalah faktor predisposisi (predisposing factors) yang mencakup pengetahuan, sikap, kepercayaan, keyakinan, kebiasaan, norma sosial, budaya dan sebagainya.

Hasil ini membuktikan masih ada faktor karatif dari perilaku caring belum diterapkan dengan maksimal oleh perawat pelaksana. Berdasarkan situasi di Rumah Sakit Tingkat II Kartika Husada Pontianak, perilaku caring antara perawat dan klien masih sangat membutuhkan kerjasama antara kedua belah pihak agar klien sebagai penerima asuhan keperawatan dapat kooperatif maka perawat diharapkan mempunyai kemampuan komunikasi terapeutik dan pengetahuan serta keterampilan dalam melakukan tindakan asuhan keperawatan yang memadai sehingga menimbulkan kepercayaan pasien terhadap perawat. Selain itu perawat pelaksana di ruang rawat inap Rumah Sakit Tingkat II Kartika Husada Pontianak masih kurang baik mempersepsikan apa yang menjadi keluhan klien dengan penuh perhatian sehingga keluarga dan klien belum dapat mengungkapkan ketakutan dan keprihatianannya selama dirawat di rumah sakit. Hal ini dapat dilakukan jika perawat pelaksana mempunyai teknik komunikasi terapeutik yang baik. Teknik komunikasi terapeutik merupakan cara untuk membina hubungan yang terapeutik dimana terjadi penyampaian informasi dan pertukaran perasaan dan pikiran dengan maksud untuk mempengrauhi orang lain (Stuart \& Laraia, 2005).

Caring dapat mempengaruhi kehidupan seseorang dalam cara bermakna, dan memicu eksistensi yang lebih memuaskan. Caring merupakan suatu proses yang memberikan kesempatan pada seseorang, baik pemberi asuhan maupun penerima asuhan untuk pertumbuhan pribadi (Morrison \& Burnand 2007). Perilaku caring Perawat dengan kebersamaan (being with) yaitu perawat yang menghadirkan diri secara emosional untuk orang lain atau klien. Perawat menjadi ada, meliputi tidak hanya kehadiran secara fisik saja tetapi juga jelas menyampaikan pesan ketersediaan dan keyakinan untuk bertahan dengan klien. Hal ini termasuk berada disana secara pribadi, menyampaikan kesediaan, dan perasaan ingin berbagi tanpa membebani orang yang dirawat 
(Swanson, 1991 dalam Tomey \& Alligood, 2006).

Caring bersifat sangat personal sehingga pengungkapan caring pada setiap pasien berbeda. Persepsi transkultural yang dikemukakan Leinenger (1988, dalam Potter \& Perry, 2009) menekankan pentingnya pemahaman perawat tentang pelayanan kultural. Perawat perlu mempelajari kebiasaan kultur yang berbeda agar dapat mengenali dan memenuhi semua kebutuhan pasien. Perilaku caring menurut pendapat Leinenger (1988) adalah aktivitas perawat yang penuh dengan keterampilan, suatu proses dan pengambilan keputusan yang berhubungan dengan membantu klien yang merefleksikan atribut sikap seperti empati, mendukung, belas kasih, melindungi, dan hal-hal lain tentang kebutuhan, nilai, masalah, nilai dan tujuan yang ingin dicapai oleh individu ataupun kelompok yang dibantu perawat.

Swanson (dalam Watson, 2009) melakukan meta analisis terhadap 130 penelitian keperawatan yang mengidentifikasi bahwa dampak perilaku caring terhadap perawat adalah timbulnya rasa cinta terhadap keperawatan sehingga perawat akan berusaha meningkatkan pengetahuan, menghargai kehidupan dan kematian, menunjukkan integritas, keutuhan dan harga diri serta perasaan puas dapat membantu klien mencapai kesehatan dan kesejahteraan. Dampak perilaku caring yang dirasakan oleh perawat ini yang diharapkan menimbulkan motivasi kerja perawat untuk mengoptimalkan kinerjanya.

Watson dengan teori of human care mempertegas bahwa caring sebagai jenis habungan dan transaksi yang diperlukan anatara pemberi dan penerima asuhan untuk meningkatkan dan melindungi klien sebagai manusia. Bentuk hubungan perawat dan klien adalah hubungan yang wajib dipertanggung jawabkan secara profesional (Tomey \& Allygood, 2006).

Kesimpulan yang dapat diambil dari beberapa pernyataan pakar diatas adalah caring yang terdiri atas dua aspek yaitu berupa tindakan nyata perawat dalam melakukan peran dan tugasnya dalam memberikan asuhan keperawatan kepada klien dan aspek afektif perawat seperti perasaan cinta, altruisme, belas kasih, kehangatan serta perasaan lain yang mendasari perawat melakukan tindakan caring kepada klien. Hasil observasi menunjukkan bahwa dalam memberikan asuhan keperawatan sebagian besar perawat telah memperkenalkan diri dan menjelaskan perannya kepada pasien, hanya saja perawat jarang menyediakan waktu khusus untuk mengkaji secara mendalam masalah yang dialami pasien dan masih ada yang kurang memberikan perhatian penuh kepada pasien, tidak menjelaskan rasional prosedur tindakan keperawatan yang akan dilakukan. Hal ini perlu menjadi pertimbangan pihak manajer keperawatan dan manajer rumah sakit untuk mempertahankan perilaku caring yang baik. Perawat yang berperilaku caring terhadap pasien berarti perawat tersebut sudah mampu memberikan pelayanan yang baik kepada pasien. Sikap caring berarti perawat bersikap empati, memberi dukungan, simpati serta perlindungan kepada pasien. Dengan menunjukkan sikap caring maka dapat memberikan pengalaman yang baik untuk pasien. Pendapat ini didukung oleh Wolf, Miller \& Devine (2010) yang menyatakan bahwa kinerja staf perawat termasuk perilaku caring dapat memberikan kontribusi besar terhadap kualitas pengalaman pasien selama dilakukan perawatan. 
Rumah Sakit Tingkat II Kartika Husada Pontianak merupakan Rumah Sakit Tipe $C$ yang sedang berkembang. Upaya yang dilakukan pihak Rumah Sakit dalam peningkatan mutu pelayanan kesehatan dimulai dari perbaikan infrastruktur sampai peningkatan SDM. Perawat sebagai caring profession merupakan salah satu bagian dari SDM di Rumah Sakit harus dapat memberikan asuhan keperawatan yang optimal sehingga mutu pelayanan kesehatan dapat ditingkatkan.

$$
\text { Perilaku caring perawat }
$$

pelaksana di Rumah Sakit Tingkat II Kartika Husada Pontianak masih perlu ditingkatkan, hal ini disebabkan oleh komunikasi yang kurang baik. Banyak perawat yang masih belum memahami tentang arti, tujuan, serta tindakan keperawatan yang berlandaskan caring sehingga pelatihan tentang caring sangat penting dalam meningkatkan perilaku caring.

\section{Hubungan Antara Pola Komunikasi dengan Perilaku Caring Perawat Pelaksana}

Hasil penelitian yang dilakukan di Rumah Sakit Tingkat II Kartika Husada Pontianak menunjukkan bahwa ada hubungan yang signifikan antara pola komunikasi dengan perilaku caring perawat. Hasil analisa hubungan pola komunikasi dengan perilaku caring perawat menunjukkan perawat pelaksana yang mempersepsikan pola komunikasi yang baik dengan perilaku caring baik sebanyak (31,5\%). Sedangkan perawat pelaksana yang mempersepsikan pola komunikasi kurang dengan perilaku caring perawat baik sebanyak $(70,0 \%)$.

Hasil analisa kuesioner didapatkan $37,5 \%$ perawat diberikan kebebasan untuk mengungkapkan penilaian hasil pekerjaan yang dilakukan oleh teman sejawat. 52,9\% perawat tidak selalu menggunakan komunikasi terapeutik saat berinteraksi dengan pasien maupun teman sejawat.

Komunikasi adalah kumpulan dari individu yang berinteraksi satu sama lain. Komunikasi yang baik menciptakan saling pengertian dan akan memperkuat kohesi dan tercapainya tujuan-tujuan kelompok yang berdampak pada tujuan organisasi (Sopiah, 2009). Perilaku anggota dapat dikendalikan dari komunikasi. Fungsi ini berjalan ketika karyawan diwajibkan untuk menyampaikan keluhan terkait dengan pelaksanaan tugas kewajiban karyawan itu didalam perusahaan (Sully, 2005).

Hasil penelitian ini didukung oleh penelitian Rodwell et al (2008) menyimpulkan bahwa ada hubungan positif dan signifikan baik secara parsial maupun simultan terhadap praktik komunikasi organisasional dengan kinerja karyawan. Penelitian oleh Sulistyo (2009) juga menekankan terdapat pengaruh yang signifikan komunikasi organisasional terhadap kinerja karyawan. Fungsi komunikasi sebagai pengendali perilaku anggota organisasi dan saat anggota organisasi menyampaikan keluhan terkait pelaksanaan tugasnya (Sully, 2005).

\section{KESIMPULAN}

Karakteristik organisasi di ruang rawat inap Rumah Sakit Tk. II Kartika Husada Pontianak sebagian besar dinilai baik oleh perawat pelaksana. Hasil observasi perilaku caring perawat pelaksana di ruang rawat inap Rumah Sakit Tk. II Kartika Husada Pontianak sebagian besar kategori baik (51\%).

Tidak ada hubungan yang signifikan antara umur, jenis kelamin, tingkat pendidikan, status perkawinan, 
masa kerja, kepemimpinan, desain pekerjaan, dukungan manajemen, sistem rewards, dan manajemen konflik. Ada hubungan yang signifikan antara pola komunikasi dengan perilaku caring perawat pelaksana di Ruang Rawat Inap Rumah Sakit Tingkat II Kartika Husada Pontianak.

Faktor yang paling dominan berhubungan dengan perilaku caring perawat di Rumah Sakit Tk. II Kartika Husada Pontianak adalah variabel pola komunikasi.

\section{SARAN \\ Manajemen Rumah Sakit}

Meninjau hasil penelitian bahwa pola komunikasi merupakan variabel yang paling dominan berhubungan dengan perilaku caring perawat pelaksana dan dengan keterbatasan yang dimiliki dalam penelitian ini maka penting untuk manajemen rumah sakit melakukan evaluasi kembali tentang penerapan pola komunikasi yang efektif terhadap perilaku caring perawat pelaksana di Rumah Sakit Tk. II Kartika Husada Pontianak.

Perlu meningkatkan kembali perilaku caring oleh perawat pelaksana di ruang rawat inap terutama pada aspek karatif menanggapi dengan rasa hormat ekspresi perasaan positif dan negatif klien dan perhatian terhadap yang dialami orang lain dalam memberikan bimbingan serta memuaskan kebutuhan manusiawi klien. Manajemen keperawatan dapat menjadi mediator yang baik untukmeningkatkan upaya bagi perawat pelaksana dalam peningkatan diri, baik pengetahuan maupun keterampilannya guna mendukung upaya pencapaian kinerja yang lebih baik seperti monitoring dan evaluasi secara terjadwal setiap 1 bulan sekali pelaksanaan perilaku caring perawat pelaksana terhadap pasien di ruangan melalui kuesioner kepuasan pasien, mensosialisasikan pelaksanaan caring di ruangan dengan membuat motto terkait dengan pelaksanaan caring terhadap pasien. Bagi perawat pelaksana juga membudayakan pelaksanaan caring perawat terhadap pasien dengan saling mengingatkan diantara teman sejawat untuk peningkatan mutu pelayanan keperawatan.

\section{Institusi Pendidikan}

$$
\text { Dapat memperkaya }
$$

kepustakaan tentang manajemen keperawatan khususnya tentang perilaku caring perawat. Selain itu sebagai masukan untuk evaluasi hasil proses pembelajaran pada institusi pendidikan keperawatan terkait manajemen keperawatan bagi penelitian keperawatan.

\section{Penelitian Selanjutnya}

Mengingat beberapa kelemahan dari penelitian ini, diharapkan dapat dijadikan data dasar untuk mengadakan penelitian yang lebih kompleks dan spesifik tentang pola komunikasi dengan perilaku caring perawat pelaksana menggunakan desain penelitian kualitatif agar lebih mendalam mengeksplorasi pengalaman perawat tentang sistem rewards dan kinerja mereka. Melakukan pengukuran yang lebih objektif dengan melakukan observasi secara langsung kepada perawat pelaksana terkait pelaksanaan perilaku caring dengan memperhatikan pasien dari kelas perawatan, observer dan waktu observasi serta menggali variabel lain dari sosiodemografis dan budaya organisasi yang dapat mempengaruhi perilaku 


\section{DAFTAR PUSTAKA}

Leininger, M.M. 1988. Care, the essence of nursing and health. Detroit: Wayne State University Press.

Marquis, B.L., \& Huston, C.J. 2010. Leadership roles and management functions in nursing theory and application. (5th Edition). Philadelphia: Lippincott Williams and Wilkins.

Morrison, P. \& Burnard, P. 2009. Caring and Communicatting: hubungan interpersonal dalam keperawatan. Edisi kedua. (Terj. Widyawati, E. Meiliya). Jakarta: EGC.

Muttaqin. 2008. Pengaruh Supervisi terhadap perilaku caring perawat pelaksana di rumah sakit umum daerah Cianjur. Tesis Program Magister IImu Keperawatan FIK UI, tidak dipublikasikan.

Notoatmojo. 2003. Perilaku dan Teorinya. Jakarta: Salemba Medika.

Notoatmodjo, S. 2009. Pengembangan sumber daya manusia, Jakarta: Rineka Cipta.

Nurachmah, E. 2010. Persepsi klien tentang asuhan keperawatan bermutu dan tingkat kepuasan. Januari 8, 2010

Nursalam. 2002. Manajemen Keperawatan: Aplikasi dalam Praktik Keperawatan Profesional, Jakarta: Salemba Medika.

Pangewa, M. 2007. Perilaku keorganisasian. Jakarta: Departemen Pendidikan Nasional.
Panjaitan, R. 2007. Hubungan efektivitas kepemimpinan kepala ruangan dengan kinerja perawat pelaksana di ruang rawat inap RSPAD Gatot SubrotoJakarta. skripsi

Pohan, I. 2007. Penjaminan mutu kesehatan. Jakarta: Salemba Medika.

Riani, A. 2011. Budaya Organisasi. Yogyakarta: Graha Ilham.

Ricardo, Ronald \& Jolly. 2003. Organization culture and teams. Academy of management journal. Volume 13.

Rivai, V. 2009. Manajemen sumber daya manusia untuk perusahaan dari teori ke praktek. Jakarta: Rajawali Pers.

Robbins, S. \& Judge, Y. 2010. Perilaku Organisasi. (Terj. D. Angelica, R. Cahyani, dan A. Rosyid) Edisi 12. Jakarta: Salemba Empat (Buku asli tahun 2007).

Rodwell, John J., Rene K, \& Mark A. 2008. The relationship among work related perceptions integral role of communication. Employess Journal of management. Vol 20.

Rubenfeld, M.G., Scheffer, B.K. (2007). Berpikir kritis dalam keperawatan. (A. Lusiyana, N. Herdina, D. Yulianti, Penerjemah). Jakarta: EGC.

Rusmiati 2008. Hubungan lingkungan organisasi dan karakteristik perawat dengan kinerja perawat pelaksana di ruangan rawat inap rumah sakit umum pusat persahabatan Jakarta. Tesis program Magister IImu 
Keperawatan FIK.UI, tidak dipublikasikan.

Setiati.2005. Hubungan faktor individu dengan perilaku caring terhadap pasien di rumah sakit. Tesis Program Magister IImu Keperawatan FIK UI, tidak dipublikasikan.

Siagian, S. 2010. Kiat meningkatkan produktivitas kerja. Jakarta: Rineka Cipta.

Simanjutak, P.J. 2011. Manajemen dan evaluasi kinerja. Jakarta: Lembaga Penerbit Fakultas Ekonomi Universitas Indonesia.

Sopiah. 2009. Perilaku Organisasional. CV Andi Offset. Yogyakarta.

Stuart, G.W., \&Laraia, M.T. 2005. Principle and practice of psychiatric nursing (8th ed.) Missouri: Elsevier Mosby.

Sugiyono. 2010. Metode penelitian kualitatif, kuantitatif dan R\&D. Jakarta: Alfabeta.

Sulistyo, H. 2009. Pengaruh kepemimpinan spritual dan komunikasi organisasi terhadap kinerja karyawan. Jurnal ekonomi dan bisnis (Ekobis). Volume 6. Hal. 21-28.

Supriatin, E. 2009. Hubungan beban kerja dan pengembangan profesional dan perilaku caring

perawat pelaksana di RS Cikini Jakarta. Tesis Program

Magister IImu Keperawatan FIK UI, tidak dipublikasikan.

Supriyadi. 2006. Hubungan karakteristik pekerjaan dengan pelaksanaan perilaku caring oleh perawat pelaksana di ruang rawat inap rumah sakit islam samarinda. Fakultas IImu Keperawatan Universitas Indonesia, tidak dipublikasikan.

Tomey, AM, \& Alligood, MR. 2006. Nursing theorists and their work. Six edition. Missouri: Mosby Elsevier.

Watson, J. 2005. Caring science as secret science. Philadelphia: Davis Company.

Wibowo. 2010. Manajemen kinerja. Jakarta: Raja Grafindo Persada.

Wolf, Z.B., Colahan, M, Costello, A., Warwick, F., Ambrose, M.S., \& Giardino

Zacher, H \& Frese, M. 2011. Maintaining a focus on opportunities at work: the interplay between age, job complexity, and the use of selection, optimization, and compensation strategies. Journal Organizational Behavior. Volume 